\title{
Last Shakespeare Plays Directed by Yukio Ninagawa: Possessed by the Power of Theater*
}

\author{
Emi Hamana \\ Tokyo Woman’s Christian University, Tokyo, Japan
}

\begin{abstract}
Yukio Ninagawa (1935-2016) was expected to achieve in a few years the great milestone of directing the complete collection of Shakespeare plays in new Japanese translations. This paper reconsiders Ninagawa's direction from a global/local perspective with a special focus on several last works directed by him: Richard II, performed by young players of the Saitama Next Theater in February 2012, which was especially intended for the local Japanese audience; Ninagawa Macbeth, which was performed in September 2015 and was a revival of the director's internationally-acclaimed production, first performed in Japan in 1980 and abroad in 1985 onwards; and Two Gentlemen of Verona, the thirty-first in his series of Shakespeare plays and seventh in his series of Shakespeare plays with all-male casts, in October 2015. His last plays were not as perfect as he was still experimenting. This paper concludes, however, that while possessed by the power of theater, his direction emits its magical and subversive power and suggestion to give the audience vital energy to live in this world of tough conflicts. He continued to hope to make global and local spectators wonder at the plays he directed.
\end{abstract}

Keywords: Shakespeare, Yukio Ninagawa, the power of theater, wonder, affect

\section{Introduction}

In a few years, Yukio Ninagawa (born in 1935, he first directed Shakespeare's play Romeo and Juliet in 1974 and died on 12 May 2016), arguably one of the most famous Japanese directors in the world, was expected to achieve the great milestone of directing the complete collection of Shakespeare plays in new Japanese translations. He would have become the third director to have done so, following Norio Deguchi (born in 1940, Deguchi directed all thirty-seven of Shakespeare's plays in six years, from 1975 to 1981) and Eizo Endo (born in 1950, Endo directed them at Itabashi Theater Center from 1980 to 2016). Ninagawa's works have been performed almost regularly in London and other foreign cities, and his productions have received attention from many scholars and reviewers, Japanese and international; while most of them appreciate his spectacular direction filled with bold visual images and original aesthetics, some criticize his interpretations as strange, unusual or bizarre. This paper reconsiders Ninagawa's directing from a global and local perspective with a focus on his last three works in 2015: Richard II, the legendary NINAGAWA Macbeth (or samurai Macbeth), and The Two Gentlemen of Verona (Incidentally, the last - the 32nd-Shakespeare play directed by Ninagawa was Measure for Measure performed at the Saitama Arts Theater from May to June in 2016).

\footnotetext{
* Acknowledgements: This paper is supported by the JSPS Grants-in-Aid for Scientific Research (No. 26370310). This paper is presented to the triennial IAUPE Conference, in London, 25-29 July 2016. Section 4: Shakespeare in Global Performance.

Emi Hamana, Ph.D., Emeritus Professor of Tsukuba University, is currently Professor of English Literature at Tokyo Woman's Christian University.
} 
Although we need more time to evaluate Ninagawa's whole career as an exponentially dynamic director and his legacy and broad influence will remain for a long time, we can now discuss his professional career not as "in progress" but as "closed".

As Alexa Huang rightly puts it in "Boomerang Shakespeare: Foreign Shakespeare in Britain,” the Bard "has become a boomerang business in the twenty-first century"; indeed he "has been transformed from Britain’s export to an import industry” (2016, p. 1094, see also Hoenselaars, pp. 1036-1038). Among other directors, such as Robert Lepage (Quebec) and Ong Keng Sen (Singapore), Ninagawa was undoubtedly one of the greatest pioneers and contributors in this thriving boomerang Shakespeare business, though his works have had conflicting receptions. ${ }^{1}$ In his obituary of Ninagawa, Michael Billington writes:

Yukio Ninagawa, who has died aged 80, was a great Japanese theater director whose work was marked by its astonishing visual bravura and its ability to harmonise Eastern and Western traditions. His first production to be seen in Britain was a Macbeth at the 1985 Edinburgh Festival that left audiences amazed by its dominant image of cascading cherry blossoms.

Later seen at the National Theater, that Macbeth marked the start of a fruitful professional relationship with the producer Thelma Holt, who over the next three decades brought seventeen Ninagawa productions to Britain: not only Shakespeare but work by Euripides, Ibsen and modern Japanese writers such as Kunio Shimizu and Haruki Murakami. The good news, for a generation that missed the famous Macbeth, is that Holt is planning to bring it back to the Barbican in London in September 2017.

Holt, Ninagawa’s friend and collaborator, said: "He was a great director because he was catholic, all-embracing and open to change and his amazing love of Shakespeare was based on a desire to discover what the author would have wanted”. Ninagawa combined, in fact, a profound sense of the past with an experimental flair that created some of the most moving and ineradicable images of modern world theater. (Billington)

Ninagawa was indeed global. Despite all the obituaries in Japan (e.g. Tanaka, Japan Times) and abroad (e.g. The Telegraph) and the great honour the Japanese government bestowed on him, no one can say that Ninagawa's productions of Shakespeare's plays were always great and successful. However, all theater people should admire his never-ending challenge and passion for directing plays, Shakespearean or otherwise, until his death. While radically resisting Western intellectual sophistication and elegance in classical realist theater or avant-garde from an Asian perspective (Ninagawa \& Hasebe, 2012, pp. 240-241, 352), Ninagawa was a director who was intensely possessed by the power of theater. In his book The Power of Theater, Ninagawa writes, “A play expresses communication and conflicts among characters. This power of theater has enabled me, excessively self-conscious and introverted, to manage to survive" (2013, p. 116, my translation). Although his definition of the power of theater, if true, sounds too plain and simple-minded, the power, nevertheless, enabled him to direct a number of plays, Western and Japanese, classic and modern. More importantly, his preoccupation with the power of theater resulted in his life-long pursuit of wonder. Ninagawa continued to hope that his spectators would wonder at all elements of the performance, theatrical or otherwise. In this connection, it might be useful to recall Stephen Greenblatt's theoretical concept of wonder presented in his

\footnotetext{
${ }^{1}$ Huang discusses "three interconnected channels" for the emergence of boomerang Shakespeare in Britain. "The first channel is intercultural borrowing” against the background of the Paris intercultural movement in the 1980s (p. 1096). The second channel is "surtitled touring productions" (p. 1097). There are several serious issues in the reception history of boomerang Shakespeare: for example, Western stereotypical expectations of non-Western directions with their special focus on their traditional visual and sensory dimensions. The third channel is "coproductions between UK and foreign artists or companies, a growth area of theater practice" (p. 1098). There are other serious political faces of boomerang Shakespeare since obviously it "is integral part of Britain's campaign for soft power and self-identity in a postcolonial global age” (p. 1100).
} 
Marvelous Possessions: The Wonder of the New World. Referring to Descartes' philosophical writing in the introduction to his seminal book, Greenblatt writes:

Wonder - thrilling, potentially dangerous, momentarily immobilizing, charged at once with desire, ignorance, and fear-is the quintessential human response to what Descartes calls a "first encounter”. (1991, p. 20)

In this paper on Ninagawa, we shall not discuss the first encounter between Europeans and non-Europeans. The point is that wonder, then and now, is bound to be "the quintessential human response" or complex curiosity or affect. It is a strong response; it can thus be an intense illusionary inward state. Furthermore, it can indicate a force that the other owns to attract the spectator; it can be an extraordinary force that the other owns to make the spectator stand still in amazement, confusion or even fear. Ninagawa was strongly been influenced by Mikhail Bakhtin's theory of the carnivalesque, which refers to a literary mode that subverts and liberates the assumptions of the dominant style or atmosphere through humor and chaos, and Ninagawa hoped to bring about this kind of complex embrace of wonder-vigorous, surprising, violent or grotesque-in theater. One of the most vital elements of his preoccupation of the power of theater lies in the theatrical power of wonder or affect; he was obsessed with making the spectators wonder at his work by all means ranging from acting to scenography. In the rest of this paper, I will discuss Ninagawa's last plays within the context of his ideas on the power of theater and wonder. ${ }^{2}$

In an interview with Ninagawa in April 2015, Yuriko Akishima mentions that several British academics and intellectuals have conservative and perennially sceptical attitudes toward foreign Shakespeare productions. Ninagawa says that he takes their response for granted and that "he directs Shakespeare plays because a Japanese or foreign audience is moved by Shakespeare plays, discovering their selves in his plays” (p. 222); in other words, he directs Shakespeare plays so that his contemporary audience can relate in some way or other to the power of theater or his theater of wonder. Ninagawa's unique achievement lies in the fact that wherever he directed a play, theaters were filled with multigenerational audiences. Furthermore, in a special TV programme after Ninagawa's death, distinguished Japanese director Amon Miyamoto admired Ninagawa's "genius of beautifully showing both human ugliness and wonderfulness, or raw chaos” (Special Interview), with great sympathy for the director's professional loneliness and great respect for his life-long challenge. Ninagawa said that "it is fun for us to encounter in a play the different self that we do not imagine having, and to develop our knowledge of the world" (Special Interview).

\section{Last Shakespeare Plays Directed by Yukio Ninagawa}

\section{Richard II}

Ninagawa had two companies of players: the Saitama Next Theater of young players and the Saitama Gold Theater of players aged 55 and older. Richard II was performed first mainly by Saitama Next’s young players, assisted by several players from Saitama Gold, in a special, empty, small stage inside the Saitama Arts Theater

\footnotetext{
2 As many references on Ninagawa's work were already available (for example, Kawai, 2008; Hamana, Connecting Cultures, pp. 25-36, 87-102; Huang, 2013), I discussed his eighth Hamlet production from the new perspective of his idea of the power of theater (Hamana, "Hamlet (2015)"). Although this paper does not address the question of wonder from a perspective of cognitive science and psychology, the function of wonder or affect is a vital research area in these studies. Incidentally, I considered cognitive approaches in theater and performing arts studies ranging from acting through scenography to spectatorship in my paper, "Translingual Performance of King Lear_Lear Dreaming (2012), Conceived and Directed by Ong Keng Sen as a Case Study-," which was for a seminar on "King Lear and Its Versions" at the World Shakespeare Congress held in Stratford and London in the summer of 2016 and will be published in 2017.
} 
in April 2015. It was then performed as a full collaboration of the two companies in February 2016, which was invited to the International Shakespeare Festival in Craiova, Romania, in April 2016, where it achieved great success.

Richard II begins vividly with approximately 30 Saitama Gold players, formally dressed in kimonos and sitting in wheelchairs. Additional 30 younger performers, wearing tuxedoes, push around their wheelchairs. This unique direction was inspired by the director's seriously-ill condition which forced him to use a wheelchair. Shortly after appearing on stage, these 60 performers suddenly start dancing to the seductive music of tango (la cumparsita). This is absolutely an amazing scene. The audience will find the director's obsession with the idea of death as the tango is a kind of dance of death here. In a TV documentary, while showing Ninagawa in the wheelchair, directing Richard II, the narrator told us that in this work "the director who himself was confronted with death sublimated death" ("Documentary: Yukio Ninagawa's Challenge") to the highest level of aesthetics of intensity and fantastic beauty, representing the universal history of human death, mortality and a little hope. This shows Ninagawa's theater of wonder par excellence. As mysteriously as the dance began, it ends and the wheelchairs and attendants return upstage into the dark. A young King Richard appears, on an electric wheelchair symbolizing his royal authority. In a later scene, Richard dances the female part of the tango with his cousin, Bolingbroke, possibly suggesting that Richard will be assaulted and murdered.

There is no connection, historical, cultural or whatsoever, between Shakespeare's late-medieval English history play and the sensuous tango that originated in Africa and allowed immigrants to vent to their stress in nineteenth century Latin America. Ninagawa employed the tango in the opening scene in order to immerse the audience in the world of the play and thus capture their attention in the first three minutes. Spectators are not only amazed by the thrilling scene but also affected by the macabre atmosphere of the extraordinary power of the tango. Ninagawa's concept of players suddenly dancing a tango might have been inspired by his direction of Kunio Shimizu's Tango at the End of Winter (1984). ${ }^{3}$ More importantly, it should be noted that when he directed Christopher Marlowe's The Tragedy of Dr. Faustus in Japan in 2010, Ninagawa employed a tango, which, of course, was not mentioned in the play's original directions; this tango emphasizes the "giving and taking of one's life" within the scene. Dr. Faustus (Mansai Nomura) danced the female part of the tango with Mephistopheles (Masanobu Katumura), and this dance represented "death as a climax of desire" (Kawai, 2016, p. 64). Richard II is usually interpreted as a thoughtful play in which the man who was dethroned and lost his identity questions the meaning of his being as well as human frailty in general. Ninagawa transformed the play into a thoughtful and dynamic play of (homoerotic) desire and death.

In addition to the amazing opening scene, Richard II is filled with bold visual effects and scenography. When Richard makes his delayed return from Ireland to England in Act 3, a vast wave sheet covers the stage, and he and the others float and crawl in the waters. The effect was spectacular and showed the fact that no one, king or otherwise, can defeat the overwhelming force of nature. When Richard is forced to give up his crown and sceptre to Bolingbroke at Westminster in Act 4.1, he tosses them away; the crown begins to rise slowly and floats high across the stage until the crown comes to rest on Bolingbroke, who holds the sceptre. Ninagawa visualizes the fact that these symbols of kingship are frail and floating. In prison, the self-deposed, solitary

\footnotetext{
${ }^{3}$ Uchida writes that while Ninagawa directed the tango dance scene in Richard II, he was inspired by Ken Russell's film Valentino (1977), which included a homoerotic tango scene between two men, Rudolph Valentino (Rudolph Nureyev) and a young man (2016, p. 47).
} 
Richard meditates on his fortune as well as human frailty:

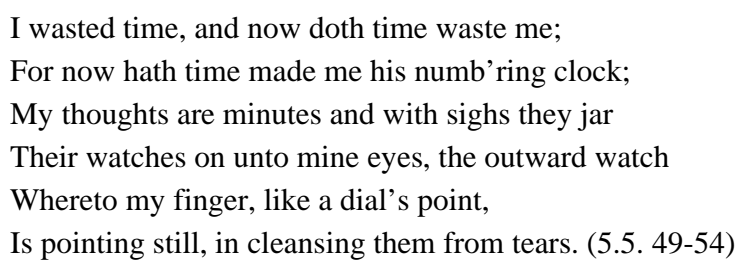

The stage floor is lit here by a large cross. Richard finally strips down to a white loincloth, reminiscent of the crucifixion of Christ. As Richard often compares his suffering to Christ's suffering, it is no wonder that he lies down at the transverse intersection of the cross with his arms perpendicular to his body within the lit cross. However, as Barry Gaines rightly points out, many "productions try to find a way to show Richard as a self-proclaimed Christ figure, but few surpass the literal crucifixion of Ninagawa's unkinged Richard.” This is indeed an amazing theatrical event.

In the final scene, Bolingbroke appears on Richard's electric wheelchair; however, there is neither real authority nor real glory. Ninagawa brilliantly exposed the vanity and folly of power struggles. Using both older and younger performers in Richard II, Ninagawa successfully creates a unique stage of wonder through their chemistry; he modernizes Shakespeare's English history play by means of vivid images and speeches that demonstrate that humans, regardless of age, cannot change their desire of power or their fate. The play ends finally with another tango between older and younger players, thus reminding the audience of the circular dynamics of history.

\section{Ninagawa Macbeth}

NINAGAWA Macbeth was originally performed in Japan in 1980 and later abroad at the Edinburgh International Festival in 1985 and the National Theater in London from 1987 onwards. Seventeen years after its last performance, this legendary work was performed at the Theater Cocoon, Shibuya, in September 2015, to celebrate Ninagawa's 80th birthday, and it will be likely performed at his memorial event in London in the autumn of 2017.

As the production is famous for its huge Butsudan (altar) set, we should remember what Ninagawa said about it:

[The play Macbeth] is set within a Buddhist family altar and everything happens within that frame... The altar is where your ancestors dwell, and the Japanese will talk to their ancestors within this setting quite naturally. It is a link between the living and the world of death. (as cited in Braunmuller, 2016, p. 1606)

Ninagawa shifted the action of Shakespeare's play to a 16th century samurai world (the age of Azuchi Momoyama) where lords were warring. Walking through two aisles of the auditorium, two crones go up to the stage and open the huge altar; in the midst of falling cherry blossom petals, Macbeth (Masachika Ichimura) and Banquo (Satoshi Hashimoto) enter in armour. While, on the one hand, it is a dazzlingly beautiful scene, on the other hand, the fully-bloomed cherry blossoms remind Japanese spectators of both the joy of life and its transience since life and death are juxtaposed in the altar. The scene represents the Japanese tradition of life and death as continuous in sharp contrast to Western views of life and death as absolutely separate.

Billington, who admired the production at the Edinburgh International Festival in 1985, writes in 
Ninagawa’s obituary:

...a play that we were used to seeing staged in Stygian gloom suddenly became a thing of wonder and beauty. No attempt was made to downplay the horror of murder: after the killing of Duncan, a dagger stuck to Macbeth's hand as if glued by blood. Even the famous cherry blossoms symbolised passing time and human transience, and the overwhelming sense of melancholy was reinforced by Ninagawa’s repeated use of the Fauré Requiem and the Samuel Barber Adagio for Strings.

Although the main cast changed between the original and later productions, Ninagawa directed the play in 2015 in its original style as Billington vividly remembers. It is, however, of some interest to know a significant difference between the first international production of Macbeth in 1985 and the revived production in 2015. While director Ninagawa, main actor Mikijiro Hira and others were all extremely nervous and stressed about the first production of Macbeth abroad in 1985, contemporary Japanese players can afford to play Shakespeare's works at ease at home and abroad thirty years later. In the NINAGAWA Macbeth programme in 2015, Producer Thelma Holt writes:

Ninagawa is a citizen of the world, like his preferred author. This year we celebrate his 80th birthday and what could be more fitting than a return to Macbeth with Masachika Ichimura in the title role and Yuko Tanaka as Lady Macbeth, both of them already favourites with the London audience. (Programme of NINAGAWA Macbeth, n.p.)

Tempted by the Witches’ equivocal prophesy and Lady Macbeth, Macbeth murders Duncan and usurps the Scottish throne. Fearing that Banquo may have discovered his role in Duncan's murder, Macbeth kills his friend, and later, Macbeth is killed by Macduff, whose wife and children were murdered. While Hira played Macbeth as a kind of superman in the original production, Ichimura, hovering between life and death, played the role rather realistically like a contemporary person stricken by self-consciousness. Unlike Komaki Kurihara who transformed herself into a kind of witch in the original production, Yuko Tanaka calmly plays the role just as she is, which is, in a sense, weirder. Furthermore, Holt writes:

We are indeed fortunate, for we have broken the barrier of language. We do use surtitles and an English-speaking audience might glance at them occasionally. However, they are merely a guideline, proving that action really does sometimes speak clearly than words. (Programme of NINAGAWA Macbeth, n.p.)

The original production was characterized by its historical-cultural shift and visualization so that the local Japanese audience could appreciate Shakespeare's Scottish tragedy, and it worked splendidly for most British and non-English-speaking spectators. The initial shocking impact of Ninagawa's theater of wonder may have decreased, yet his Macbeth is the quintessence of his theater of wonder in terms of its theatrical power, visual beauty and weirdness (e.g. the huge altar, cherry blossoms, the Witches in Kabuki style and violent fights); it is a kind of dialogue between the living and the dead, or the past and the present, at the altar. Ninagawa's ability to synthesize sound, colour and space remains amazing and fresh, if a little familiarized. However, we should not focus solely on his spectacular audio-visual effects since he also gave strict directions to the players on how to deliver Shakespeare's speeches even in the Japanese version. For these reasons, Ninagawa was highly successful in bringing about the power of theater as communication, particularly its nonverbal elements.

\section{The Two Gentlemen of Verona}

Ninagawa started to direct an all-male Shakespeare series in the twenty-first century for two reasons. First, only male players, adults and boys, were available in Shakespeare's age, and second, he hoped to produce not 
only a classic play but also a fresher and accessible play or "a new Shakespeare” (Akishima, 2015, p. 131) for Japanese spectators. He directed six plays in his all-male series: As You Like It (2004), The Comedy of Errors (2006), Love's Labour's Lost (2007), Much Ado About Nothing (2008), The Taming of the Shrew (2010), and The Merchant of Venice (2013). As Japanese Kabuki was traditionally an all-male performance, Japanese people are familiar with onnagata or oyama, male actors who played women's roles in Kabuki theater. In fact, a highly talented and popular Kabuki actor Kamejiro Ichikawa (Ennouke Ichikawa IV now) played Katharina with great skill and a brilliant sense of humor in The Taming of the Shrew. However, the all-male series were generally characterized by young players and popular stars in the main roles.

The Two Gentlemen of Verona, the thirty-first in Ninagawa's series of Shakespeare plays and seventh in the all-male series, was performed in October 2015. The main cast included three popular stars: Junpei Mizobata (Julia), Ryosuke Miura (Proteus) and Mitsuomi Takahashi (Valentine). It also included Ninagawa's form of onnagata, Yuki Tsukikawa (Silvia). The play is of great interest as one of Shakespeare's early comedies.

Julia is the first of Shakespeare's heroines in male disguise, a device whose usefulness to boy players Shakespeare would continue to exploit in later plays. Julia's predicament as the servant of the man she loves, employed by him to woo another woman, anticipates that of Viola in Twelfth Night, and the name she adopts in disguise, "Sebastian," is that of Viola's twin brother. (Shakespeare, 1998b, p. 1217)

Employing the devise of cross-dressing and disguise, The Two Gentlemen of Verona enacts a total confusion of gender (and sexuality) throughout. As its perfunctory ending shows, however, the play is obviously not a masterpiece, and Ninagawa's interpretation remained rather conventional.

In her book on As You Like It, Lesley Wade Soule writes that the boy actor who played Rosalind had “charisma," "the uncanny” and "otherness," although we do not yet know much about him, not even his name (p. 112). The boy actor is considered to have had a charm that derived from the tradition of devils and fools in religious rituals, folk or popular festivals and entertainment in the Middle Ages. On the other hand, he probably bore the uncanny characteristic of an adolescent on the threshold between childhood and adulthood. It is improbable to find such radical otherness and epistemological impact as Julia/Sebastian in The Two Gentlemen of Verona, directed by Ninagawa. Yet, certainly Julia/Sebastian as well as Sylvia had a peculiar charm and attraction. It was therefore in a sense "a new Shakespeare.” Although most of the Japanese spectators were delighted to watch it, I have to admit that it lacked something truly imaginative and insightful; it did not fully utilise the all-male cast to shed new light on the cognitive questions and aesthetics of gender, sexuality and homoerotic desire on the contemporary stage.

While Ninagawa's production of The Two Gentlemen of Verona was relatively conventional, his effective use of aisles of the Saitama Arts Theater is noteworthy. The Saitama Arts Theater has four specialist halls suitable for staging theatrical art forms, such as plays, dance, music and audio-visual performances. The main proscenium theater is used to stage plays, musicals, operas, ballets and contemporary dance performances. "The auditorium is the ideal size for conveying the human voice, while the seating layout enables the audience to fully engage in the live experience" ("Main Theater"). The main theater also has one of the biggest stages in Japan, as well as the latest in stage machinery, lighting and acoustic technology. The theater has a total of 776 seats with 610 seats on the 1st floor and 166 seats on the 2nd floor.

The structure of this theater (stage with huge depth and auditorium) is of vital importance for the 
popularity of Ninagawa's Shakespeare plays. Although he was able to use the large stage provided with the whole set of high-tech devices as flexibly as possible, I would like to focus on the four aisles on the first floor in particular. He used the central two aisles as a kind of hanamichi, which is an extra stage section used in Kabuki theater. The proper Kabuki hanamichi is a long, raised platform that runs from the back of the theater, left of centre, through the audience and connects with the main stage. Generally, it is used for characters' entrances and exits, though it can also be used for asides or scenes taking place apart from the main action. In this use, it can be seen as an alley theater connected to a larger stage. Ninagawa used aisles flexibly and effectively to involve the audience in the play's action. While supporting characters put up props, including a flag of Verona, on the stage, The Two Gentlemen of Verona begins with the dramatic entrance of the two protagonists. Valentine, who is leaving for Milan, and Proteus emerge from two doors and exchange dialogue as they walk up the second and the third aisles, thus making the spectators immediately feel as if they were in the play. Many other characters enter and deliver their speeches in the aisles as if they were in the streets of Verona or Milan. As he did with other comedies, Ninagawa transformed the whole theater, both the stage and the auditorium, into a kind of carnival space.

Ninagawa used the whole auditorium (all the four aisles and the spectators in the seats) effectively especially during his productions of Shakespeare's English and Roman history plays, which normally struggle to maintain the interest of average Japanese spectators. For example, in the famous scene (3.3) of Julius Caesar, performed in 2014, Brutus and Antony delivered their speeches to the spectators as if they were Roman citizens. Ninagawa excelled in casting the audience into the illusory roles of English commoners, involving them in the action of the historical play as its pseudo-witnesses or participants, letting them reflect on the historical similarities and differences between the West and the East. Ninagawa's use of the Saitama Arts Theater's structure during the production of The Two Gentlemen of Verona was limited; he used it conventionally to invite the spectators to the theatrical space. His use of the theatrical affordance and environment to direct the play and his deliberate method of involving the spectators in the festive space of the play are nevertheless highly effective and entertaining.

\section{Conclusion}

Although Ninagawa was possessed by the power of theater even in his seriously-ill condition and directed several Shakespeare plays, his last plays were not as perfect as he was still experimenting with the medium. His concept of the power of theater as communication seems less innovative in the age of post-dramatic, performative and intermedial turn. Regardless of legitimate or questionable critiques of his directing, however, we cannot deny that his bold, imaginative and visual direction yields fabulous theatrical effects and that his power of theater successfully and immediately grabs the audience's attention, thus immersing them in the play's world. In sharp contrast to Peter Brook’s extreme minimalism, Ninagawa's direction, full of noise and sometimes excessive for ordinary old and young people, emits its magical and subversive power and suggestion to give the audience vital energy to live in this world of tough conflicts. While trying to affect spectators' senses as well as their reason and intellect, he continued to hope to make global and local spectators wonder at the plays he directed. 


\section{References}

Akishima, Y. (2015). Yukio Ninagawa and William Shakespeare. Tokyo: Kadokawa Shoten.

Anonymous. (26 May 2016). Yukio Ninagawa theater director-Obituary. The Telegraph. Retrieved from http://www.telegraph.co.uk/obituaries/2016/05/26/yukio-ninagawa-theater-director--obituary/

Billington, M. (16 May 2016). Yukio Ninagawa obituary. The Guardian. Retrieved from https://www.theguardian.com/stage/2016/may/16/yukio-ninagawa-obituary/

Braunmuller, A. R. (2016). Macbeth, three influential late twentieth-century productions: Kurosawa, Polanski, Ninagawa. In B. R. Smith, et al. (Eds.), The Cambridge guide to the worlds of Shakespeare (Vol. 2, pp. 1604-1607). Cambridge: Cambridge University Press.

Gaines, B. (30 April 2016). Monumental Japanese production of Shakespeare’s Richard II opens Romanian festival. Retrieved from

https://barryreviews.wordpress.com/2016/04/30/monumental-japanese-production-of-shakespeares-richard-ii-opens-romania n-festival/

Greenblatt, S. (1991). Marvellous possessions: The wonder of the new world. Oxford: Oxford University Press.

Hamana, E. (2012). Connecting cultures from Shakespeare to contemporary Asian theater (In Japanese). Tokyo: Tsukuba University Press.

Hamana, E. (Forthcoming 2017). Last Shakespeare plays directed by Yukio Ninagawa: Possessed by the power of theater. In K. Kujawinska-Courtney and G. Zinkiewicz (Eds.), Shakespeare: His infinite variety. Lodz: Lodz University Press.

Hoenselaars, T. (2016). International encounters. In B. R. Smith, et al. (Eds.), The Cambridge guide to the worlds of Shakespeare (Vol. 2, pp. 1033-1046). Cambridge: Cambridge University Press.

Huang, A. (2016). Boomerang Shakespeare: Foreign Shakespeare in Britain. In B. R. Smith, et al. (Eds.), The Cambridge guide to the worlds of Shakespeare (Vol. 2, pp. 1094-1101). Cambridge: Cambridge University Press.

Huang, A. C. Y. (2013). Yukio Ninagawa. In P. Holland (Ed.), Brook, Hall, Ninagawa, Lepage. Great Shakespeareans (Vol. XVIII, pp. 79-112). London: Bloomsbury.

Kawai, S. (2008). Ninagawa Yukio. In J. R. Brown (Ed.), The Routledge Companion to Directors' Shakespeare (pp. 269-283). London: Routledge.

Kawai, S. (May 2016). The significance of producing Richard II for the Saitama Shakespeare Series. Higeki Kigeki, (No. 780, pp. 62-64). Tokyo: Hayakawa Shobo.

Ninagawa, Y. (2013). Engeki no Chikara (The power of theater). Tokyo: Nihon Keizai Shinbun Press.

Ninagawa, Y. (28 May 2016). Special interview with Yukio Ninagawa theater director. [TV programme]. NHK 1.

Ninagawa, Y. (4 June 2016). Documentary: Yukio Ninagawa’s challenge. [TV programme]. NHK BS Premium.

Ninagawa, Y., \& Hasebe, H. (2012). Engijutsu (The art of direction). Tokyo: Chikuma Shobo.

Programme of NINAGAWA Macbeth. (2015). Tokyo: Hori Production Inc.

Saitama Arts Theater. (26 June 2016). Main theater. Retrieved from http://www.saf.or.jp/en/venues/arthall.html/

Shakespeare, W. (1998a). Richard II. In R. Proudfoot, et al. (Eds.), The Arden Shakespeare complete works (pp. 669-698). Surry: Thomas Nelson.

Shakespeare, W. (1998b). The two gentlemen of Verona. In R. Proudfoot, et al. (Eds.), The Arden Shakespeare complete works (pp. 1217-1240). Surry: Thomas Nelson.

Soule, L. W. (2000). Actor as anti-character: Dionysus, the devil, and the boy Rosalind. Westport, Connecticut: Greenwood Press.

Tanaka, N. (13 May 2016). World was a stage for acclaimed theater director Yukio Ninagawa. Japan Times. Retrieved from http://www.japantimes.co.jp/culture/2016/05/13/stage/world-was-a-stage-for-acclaimed-theater-director-yukio-ninagawa/\#.V 02aWZGLSUk/

Uchida, K. (May 2016). Baptized by Ninagawa Shakespeare. Higeki Kigeki, (No. 780, pp. 46-49). Tokyo: Hayakawa Shobo. 